\title{
a obra de alice canabrava na historiografia brasileira ${ }^{1}$
}

Flávio Azevedo Marques de Saes

Professor Titular - FEA/USP

Se algum pesquisador fizer um levantamento da historiografia brasileira nos anos quarenta e cinqüenta, encontrará vários títulos de história econômica - entre livros e artigos — assinados porA. P. Canabrava. Se for um jovem pesquisador estrangeiro tendo seu primeiro contato com a historiografia brasileira, certamente ficará intrigado com a abreviatura, perguntando-se quais os nomes ocultos sob essas iniciais. Ao compulsar as publicações de A. P. Canabrava e confrontando-as com os demais títulos da historiografia da época, certamente notará algumas características distintivas de sua obra - seja pelos temas tratados, seja pelo método de abordagem, seja ainda pela natureza da pesquisa realizada. E talvez se mostrará surpreso ao saber que tais iniciais ocultavam um nome feminino - o de Alice Piffer Canabrava — pois ainda eram poucas as historiadoras brasileiras naquela época.

Ao propor este contato imaginário com a historiografia brasileira dos anos quarenta, quero ressaltar dois temas que exigem uma atenção particular ao se tratar da obra de Alice Canabrava: de um lado, a natureza peculiar de sua pesquisa em história econômica e, do outro, o fato de uma mulher estar encetando uma expressiva carreira na Universidade, numa época em que a presença feminina era ainda pouco marcante. Convém prevenir desde logo que o viés deste artigo é o da história econômica, e não o da história de gênero. A questão do gê-

1 Texto apresentado no Simpósio "A participação feminina na construção de novas disciplinas: o caso da historiografia econômica no Brasil”, coordenado pelo professor Tamás Szmrecsányi, no V Congresso Latino-Americano de História das Ciências e da Tecnologia (Rio de Janeiro, 28 a 31 de julho de 1998), promovido pela Sociedade Latino-Americana de História das Ciências e da Tecnologia. 
nero só é levantada por mim como parte das notas biográficas de Alice Canabrava, e o seu tratamento específico exigiria a atenção de pesquisadores mais bem qualificados para essa empreitada. De qualquer modo, procurarei abordar estes dois aspectos da carreira da historiadora Alice Canabrava, já que em ambos entendo haver certo pioneirismo em sua atuação.

\section{Breve Nota Biográfica: da Escola Normal à Cátedra de História Econômica ${ }^{2}$}

Alice Canabrava nasceu em Araras, Estado de São Paulo, em 1911. Araras situa-se próxima de Campinas, numa região, então, tipicamente cafeeira. Aliás, sua família tinha uma propriedade de médio porte que fora doada peloVisconde de Nova Granada ao avô de Alice Canabrava. Este era médico naquela cidade e, tendo tratado do Visconde, recebeu cem alqueires como "agradecimento" (Canabrava, 1997:162). O sobrenome Piffer vem de sua mãe, nascida na Áustria, e que, segundo a própria Alice Canabrava, estava habituada ao trabalho árduo, e não via razões para a mulher se abster do estudo e do trabalho. Seu pai, com raízes brasileiras, era homem culto, afeito à leitura, e também não admitia a inferioridade feminina em relação às tarefas intelectuais. Definiram-se, assim, desde a infância de Alice Canabrava duas influências que, embora distintas, confluíam ao afirmar o valor do estudo e do trabalho para a mulher.

Concluído o curso primário, Alice Canabrava fez o ginásio, como interna, no Colégio Stafford em São Paulo. ${ }^{3}$ Posteriormente, ingressou na Escola Normal da Praça da República, também na cidade de São

2 A maior parte destas notas biográficas reproduz informações colhidas em conversas informais com a Professora Alice Canabrava e também em dois depoimentos feitos por ela: para a revista Economia Aplicada [Canabrava (1997)] e para uma série sobre as mulheres na Universidade de São Paulo, organizada pela Prof., Eva Blay [Canabrava (s/d)]. Esta série foi objeto de um artigo em que trechos dos depoimentos são reproduzidos [Blay e Lang (1984)]. Na medida do possível, estas informações relativamente subjetivas foram confrontadas com fontes documentais. É claro que sempre permanece a possibilidade de um duplo viés: o da própria Professora Alice Canabrava e o do autor deste artigo tentando "interpretar" as informações por ela fornecidas.

3 Alice Canabrava nos lembra que ela e sua irmã foram as duas únicas meninas de Araras, à época, que prosseguiram os estudos além do primário e num ginásio da capital (Canabrava, s/d). 
Paulo. Evidentemente, nos anos vinte, a formação educacional de uma menina tinha como alvo máximo a conclusão do curso normal com o eventual ingresso no magistério primário. Em São Paulo, a Escola Normal da Praça definia o padrão de qualidade desse nível de ensino. É claro, no entanto, que para uma menina do Interior deslocar-se para cursar em São Paulo, primeiro o ginásio, e depois a escola normal, envolvia uma decisão familiar forte e a superação de uma série de obstáculos materiais. Portanto, um ambiente que valorizasse a educação seria fundamental para que essa decisão fosse levada adiante.

Concluído o curso normal, no final dos anos vinte, a perspectiva que se apresentava a Alice Canabrava era o ingresso no magistério oficial. ${ }^{4}$ Efetivamente foi isso que ela fez, indo lecionar em Manduri, um pequeno distrito do Interior, próximo a Piraju (na região da Sorocabana). Algum tempo depois conseguiu sua transferência para Araras, continuando ali a dedicar-se ao magistério primário. Embora se refira sempre a essa experiência com grande satisfação - especialmente na tarefa de alfabetização de crianças - sentia também a limitação de horizontes que a atividade impunha. Mesmo em Araras, procurava, pela encomenda de livros na Capital e pelas aulas de francês que recebia de um suíço morador na cidade, superar as limitações culturais inerentes ao ambiente local. Ao mesmo tempo, em busca de alternativas, consultava o Diário Oficial na esperança de que surgisse alguma oportunidade que lhe permitisse novos vôos. Essa oportunidade finalmente apareceu em 1934.

Como se sabe, naquele ano foi fundada a Universidade de São Paulo, que agregava algumas faculdades já existentes - como as de Medicina, Direito, Engenharia, Agronomia além do Instituto de Educação e alguns elementos das Escolas de Veterinária, Farmácia e Odontologia ${ }^{5}$ - e criava uma nova Faculdade - a de Filosofia, Ciências e Letras.

4 Vale notar que o regime educacional da República Velha definia o ensino normal (e alguns cursos "técnicos" como o de comércio) como um "fim de linha". O diploma de "normalista" só permitia o exercício do magistério (assim como o do ensino comercial só conduzia ao exercício da atividade de contador e outras correlatas); ele não habilitava o seu portador a candidatar-se a uma vaga na Universidade (nos cursos de Medicina, Direito, Engenharia e outros). Para tanto, seria preciso retomar os estudos nos ginásios ou liceus, praticamente recomeçando o processo educacional.

5 Americano, Jorge. A Universidade de São Paulo, São Paulo, Revista dos Tribunais, 1947. 
"A situação atual do mundo, as ameaças de uma catástrofe próxima que pesam sobre os povos, o desrespeito às leis internacionais e aos tratados, não mais permitem a existência de países fracos, objeto da cobiça de povos fortes (...). Só as nações fortes, econômica e militarmente, estão hoje, em condições de, provendo sua defesa, poder subsistir e viver com dignidade (...). o Brasil precisa constituir-se, o mais rapidamente possível em grande potência (....). Possui vários fatores determinantes para isso; falta-lhe, porém, o desenvolvimento industrial (...). Impõe-se, então, a organização da indústria pesada, para ficar em condições de, com outros povos, sentir-se confiante no seu progresso e segurança" (GV 39.05.11/2) ${ }^{1}$.

A propósito da idéia segundo a qual a industrialização é essencial à manutenção da independência nacional, parece ter ocorrido uma convergência entre os discursos de setores da burocracia e da liderança da burguesia industrial, que, pelo menos desde o final dos anos 1920, vinham procurando identificar a industrialização com o interesse nacional, como forma de combater o pensamento antiindustrialista (Diniz, 1978).

As transformações em curso na sociedade brasileira também induziam à tomada de consciência sobre a importância do fomento à indústria. A sociedade que emergiu da crise de 1929 e da Revolução de 1930 era bem diferente da do período anterior, embora muito das novas características fossem desdobramentos de processos desencadeados ainda na RepúblicaVelha. O Brasil começava a deixar de ser uma sociedade fundamentalmente agrária para se tornar uma sociedade urbanoindustrial. A indústria tinha-se tornado o setor dinâmico da acumulação de capital. A estrutura de classes ganhou maior complexidade, com o crescimento acelerado do proletariado e de outros setores urbanos. A burguesia industrial ganhou mais peso econômico e político. Além disso, o clima da época era marcadamente nacionalista.

Essas mudanças já eram visíveis por volta de meados da década de 1930. Em 1934, em carta a Aranha,Vargas escreveu: "o renascimento

1 As referências dos documentos pesquisados nos Arquivos Getúlio Vargas (GV), Osvaldo Aranha (OA) e Sousa Costa (SC), do Centro de Pesquisa e Documentação de História Contemporânea do Brasil (CPDOC) da Fundação Getúlio Vargas (FGV), indicam o código de localização dos documentos com base na data de cada um. Os números após a sigla indicam a data do documento, na seguinte ordem: ano, mês e dia. 
econômico é palpável (...) nas fábricas trabalha-se intensamente" (apud Hilton, 1977:47). Quatro anos mais tarde, afirmaria:

"Já atravessamos a fase crítica da monoprodução (...). Em lugar de recebermos gêneros de alimentação e artigos industriais de imediato consumo, precisamos importar máquinas para fabricação de outras máquinas e amparar as indústrias de base (...). Cumpre-nos, pois, dirigir, cuidadosamente, a importação, controlar o que recebemos de modo sistemático, a fim de evitarmos a drenagem do ouro na importação de superfluidades (...). Por esta forma, incrementaremos numerosas indústrias no País, adquiriremos técnicas novas e desdobraremos a capacidade de consumo do mercado interno" (Vargas, 1942:129-130).

Nas circunstâncias da época, seria plausível esperar que Vargas começasse a apostar cada vez mais no setor industrial, pois a superação da crise e a manutenção do crescimento econômico seriam elementos importantes para satisfazer anseios e interesses de diferentes setores sociais e para costurar uma sólida base de sustentação política. Também começava a ficar claro que a própria continuidade do crescimento carecia de substancial ampliação da infra-estrutura e da oferta de bens de capital, setores cuja expansão dependia, em boa medida, da ação estatal.

Este ponto foi bastante discutido por Fonseca (1989), que mostrou que, entre o período da Aliança Liberal e o Estado Novo, o discurso de Vargas evoluiu do ceticismo sobre a indústria para a defesa de um desenvolvimento nela calcado. A percepção cada vez mais clara de que a indústria seria um elemento chave para o futuro do País foi importante para o amadurecimento do projeto nacional de desenvolvimento de Vargas.

\section{O Estado Novo e o Esboço de um Projeto de Desenvolvimento}

Ao mesmo tempo que começava a tomar corpo a idéia de que seria imprescindível incrementar rapidamente o desenvolvimento nacional calcado na indústria, o governo Vargas adotava uma política externa mais independente, aproveitando os espaços abertos pelo acirramento das disputas interimperialistas. O cerne dessa nova postura era uma maior aproximação comercial e militar à Alemanha. Essa aproximação 
dos resultados obtidos deram a Alice Canabrava uma posição de destaque entre os jovens historiadores brasileiros da época.

Tendo sido aberto um concurso para a cátedra de História da América, Alice Canabrava dedicou-se à elaboração da tese com a qual iria concorrer - A Indústria do Açúcar nas Ithas Inglesas e Francesas do Mar das Antilhas, 1697-1755. Nesse concurso inscreveu-se outro candidato, Astrogildo Rodrigues de Mello, professor então contratado para reger a cátedra. Alice Canabrava relata que passou a sentir uma enorme resistência entre seus colegas a partir do momento em que, pela repercussão de sua tese de doutoramento, aparecia como candidata potencial à cátedra:

"Deste modo, involuntariamente emergi, aos olhos de meus colegas masculinos, como possível candidata ao provimento efetivo da cadeira de História da América, a ser posta em concurso. Até então, o relacionamento com esses colegas havia sido muito afável, direi até não isento de estima pessoal. A partir de então, o círculo de hostilidade subterrânea começou a se desenhar para mim com evidências, a se apertar anonimamente em uma ou outra ocorrência da atividade universitária, sem alterar a aparência de superficial cordialidade. (...) A pesquisa histórica, desde minha licenciatura, absorvia cotidianamente muitas das minhas horas; reservava as férias para o trabalho na Biblioteca Nacional e no Arquivo Nacional, no Rio de Janeiro. Passei então a solicitar documentação da Biblioteca do Congresso dos Estados Unidos referente às Antilhas e logo percebi que esta correspondência, cartas e caixas com rolos de microfilmes, chegava violada. O mesmo acontecia com as cartas trocadas com a Fundação Rockfeller, com a qual estava tentando obter uma bolsa de estudo, de alguns meses, para consultar os arquivos de algumas ilhas daquela área. Na biblioteca da Faculdade, qualquer obra que requisitasse, ou estaria fora do lugar ou, após a primeira consulta, não seria mais encontrada para prosseguimento."

"Outras armadilhas não lograram êxito, e delas tive conhecimento após vários anos passados. A livraria onde comprava a maior parte dos livros para pagá-los mensalmente, ao todo ou em parte, foi avisada do risco que incorria, mas não considerou a advertência com base nas relações de muitos anos. Um funcionário da Faculdade, como o mesmo me contou em anos recentes, foi incumbido de me seguir diariamente e dar conta dos lugares que freqüentava. Ouvi conselhos e insinuações de que não devia desafiar a hostilidade já 
constituída: iria ser fatalmente reprovada. A minha resposta foi invariavelmente a mesma, sem qualquer argumento: "Eu faço o concurso, caberá à banca me reprovar". Ao encerramento do prazo para a inscrição no concurso, o elevador parou de funcionar no momento em que me apresentei. Fomos obrigados a galgar a pé os lances de escada que levavam ao segundo andar do edifício da Praça da República, a Escola Normal Caetano de Campos, carregando nos braços, em algumas viagens, os cem exemplares da tese exigidos pelo edital. $\mathrm{Na}$ secretaria aguardavam o encerramento alguns de meus contrários, mas com todas as dificuldades, eu lograra me manter dentro do prazo para a inscrição. A tese havia sido impressa em minha casa, em mimeógrafo usado, adquirido para a ocasião, receosa de que vistoriassem as principais firmas do gênero, o que de fato aconteceu, para tentar bloquear meu trabalho na fase final." (Canabrava, s/d).

Alice Canabrava, embora com média mais alta, recebeu menos indicações da banca examinadora, tendo obtido nesse concurso apenas o título de livre-docente. Inconformada com o que lhe pareceu uma injustiça, não quis permanecer na Faculdade de Filosofia. Naquele ano de 1946 fora criada a Faculdade de Ciências Econômicas e Administrativas da USP e, com ela, o Instituto de Administração. Alice Canabrava ingressou, então, no Instituto de Administração (no qual fez várias pesquisas sobre a história da administração municipal em São Paulo, publicadas na Revista de Administração) e, um pouco mais tarde, passou a reger a cátedra de História Econômica Geral e Formação Econômica do Brasil da Faculdade de Ciências Econômicas e Administrativas. Em 1951, com a tese O Desenvolvimento da Cultura do Algodão na Província de São Paulo, 1861-1875, conquistou, por concurso, a cátedra. Tornouse, assim, uma das primeiras (senão a primeira) mulher a assumir uma cátedra na Universidade de São Paulo. ${ }^{8}$

$\mathrm{Na}$ Faculdade de Economia da USP encontrou ambiente mais acolhedor e desenvolveu longo trabalho didático e de pesquisa, criando

8 Em 1952, o Guia da USP registrava, além de Alice Canabrava, catedrática de História Econômica da Faculdade de Ciências Econômicas e Administrativas, as seguintes professoras como regentes da cátedra (embora não haja informação de serem ou não concursadas): Vera Helena Amaral (Desenho Artístico, Faculdade de Arquitetura e Urbanismo); Anita Marcondes Cabral (Psicologia) e Noemy Silveira Rudolfer (Psicologia Eduicacional) na Faculdade de Filosofia, Ciências e Letras (Guia da Universidade de São Paulo,1951-52, São Paulo, Reitoria da USP, 1952). 
uma imagem que, por seu rigor e seriedade, era conhecida até mesmo pelos candidatos ao vestibular. Como catedrática da Cadeira X (História Econômica Geral e Formação Econômica do Brasil) e depois titular do Departamento de Economia, agregou a seu redor um grupo de assistentes que, em especial nos anos setenta e oitenta, desenvolveu pesquisas sob sua orientação. ${ }^{9}$ Em 1981 aposentou-se compulsoriamente, depois de mais de cinqüenta anos de dedicação ao magistério, mas manteve ainda suas atividades de pesquisa.

Convém lembrar também sua atuação na ANPUH - Associação Nacional dos Professores Universitários de História. Fundadora da entidade em 1961 - ainda como APUH - foi durante longo tempo sua Secretária-Geral, dividindo com o Prof. Eurípedes Simões de Paula, seu Presidente, a tarefa de manter em atividade a Associação, apesar das dificuldades materiais inerentes a esse tipo de entidade. Por meio de seus simpósios nacionais e regionais, a ANPUH foi um importante vetor para a difusão da pesquisa histórica no Brasil, principalmente numa época em que os cursos de pós-graduação ainda não existiam ou se concentravam em poucos centros universitários. Também nessa perspectiva, e já sob a presidência de Alice Canabrava, foi fundada, em 1981, a Revista Brasileira de História, publicação que, de certo modo, veio preencher a lacuna deixada pela interrrupção da periodicidade da Revista de História (do Departamento de História da USP), após a morte do Professor Simões de Paula.

Esta breve nota biográfica nos sugere alguns comentários sobre o percurso de Alice Canabrava, que a distinguem da média do elemento feminino de sua geração. Antes de mais nada, o simples fato de prosseguir na Capital os estudos além do primário já demonstra um horizonte mais amplo do que o prevalecente para as mulheres à época. Certa-

9 Suas primeiras assistentes, ainda nos anos quarenta, foram Maria Celestina Teixeira Mendes e Miriam Lifschitz, ambas formadas pela Faculdade de Filosofia, Ciência e Letras da USP. Nos anos cinqüenta outros historiadores e cientistas sociais formados pela USP passaram pela Cadeira X, como Fernando Henrique Cardoso, mados pela USP pas Fernando Novis e Jose Albertino Rodrig, co A partir dos ansistentes foram, em geral, ex-alunos da Faculdade de Ciências Econômicas e Administrativas da USP, muitos dos quais também tiveram sua orientação em dissertações de mestrado e teses de doutorado como Antonio Emílio Muniz Barreto, Ronaldo Marcos dos Santos, Iraci del Nero da Costa, Francisco Vidal Luna, Nelson H. Nozoe, Zélia M.Cardoso de Mello e o autor deste artigo. Cf. Canabrava, Alice Piffer (coord), História da Faculdade de Economia e Administração da Universidade de São Paulo (1946-1981), Volume Dois - Personália, São Paulo, FEA-USP, 1984. mente, o ambiente familiar propício respondeu por essa possibilidade, que não era comum na época. Não se deve, porém, deixar de reconhecer sua própria determinação quando, concluído o curso normal, não se contentou com essa situação. É certo que pôde beneficiar-se das mudanças que se processavam então no sistema educacional, abrindo aos normalistas o acesso à Universidade. Também é certo que entre os alunos da Faculdade de Filosofia havia várias mulheres. Mesmo assim, o seu percurso pessoal denota uma profunda determinação em busca de objetivos que, se não podiam ser claramente definidos de início (pelas próprias limitações legais impostas), foram sendo construídos com persistência e obstinação. Ainda mais expressivo, no entanto, foi seu percurso após a conclusão do curso de História e Geografia. O ingresso na carreira docente também não era exclusivo dos homens, mas tudo indica que a ascensão a postos mais elevados era vista como uma ameaça ao domínio masculino. Ainda hoje, cinqüenta anos após a ocorrência desses fatos, não é difícil imaginar as restrições que se impunham à mulher naquela época. Por mais que o relato de Alice Canabrava contenha uma alta dose de subjetividade, entendo que ele expressa uma real situação da mulher em qualquer ambiente de trabalho nos anos quarenta. Neste sentido, o seu percurso teve caráter pioneiro, ao conseguir superar os obstáculos que a ela se opuseram.

Seu sucesso, no entanto, não pode ser explicado apenas em termos da sua tenacidade em enfrentar os obstáculos. Ele foi fruto também de um dado objetivo - qual seja, a qualidade de seu trabalho de pesquisa, que acabou por impor-se face à resistência oposta pelo elemento masculino. É a esse aspecto do percurso de Alice Canabrava que nos voltamos a seguir.

\section{A Obra de Alice Canabrava na \\ Historiografia Econômica do Brasi}

Da mesma forma que a trajetória profissional de Alice Canabrava nos mostra um elemento de pioneirismo, suas pesquisas de história econômica também se revestem do mesmo caráter.

No Brasil dos anos quarenta, a História Econômica não era uma disciplina bem definida. Ainda assim, as duas teses que Alice Canabrava apresentou à cadeira de História da América da Faculdade de Filosofia, Ciências e Letras da USP (e que lhe deram os graus de doutora e de livre-docente) podem ser classificadas inequivocamente como pesquisas de História Econômica.Trata-se de algo visível nos títulos de ambas: 
O Comércio Português no Rio da Prata, 1580-1640 (defendida em 1942) e A Indústria do Açúcar nas Ilhas Inglesas e Francesas do Mar das Antilhas, 1697-1755 (de 1946). O mesmo se pode dizer de O Desenvolvimento da Cultura do Algodão na Província de São Paulo, 1861-1875 (de 1951), tese com que conquistou a cátedra de História Econômica da Faculdade de Ciências Econômicas e Administrativas da USP. Essas três obras constituem o núcleo de uma primeira fase das pesquisas históricas de Alice Canabrava e a vinculam claramente à História Econômica. Como situálas diante do que se produzia em termos de história econômica no Brasil à época?

A produção historiográfica no Brasil antes de 1930 foi dominada pelo padrão do Instituto Histórico e Geográfico Brasileiro, fundado em 1838 , e esse padrão era disseminado pelos institutos provinciais. Carlos Guilherme Mota (1978:28) a caracterizou como "a historiografia da elite oligárquica, empenhada na valorização dos feitos dos heróis da raça branca". Embora predominasse, no âmbito acadêmico, uma história "positivista" (que, por sua própria natureza privilegia os aspectos políticos), podemos encontrar alguns historiadores voltados a temas econômicos (e sociais). O próprio Taunay, com suas obras sobre café e bandeiras foi um deles. Suas pesquisas, de inegável valor, restringemse, no entanto de forma quase exclusiva a uma compilação exaustiva das fontes. Seu sucessor na cadeira de História do Brasil da Faculdade de Filosofia, Ciências e Letras da USP - Alfredo Ellis Jr. pode ser visto como um continuador da obra de Taunay. Entretanto, Capelato, Glezer e Ferlini (1995:19) entendem que Ellis sofreu também a influência de Capistrano de Abreu, historiador que teria aberto novos rumos à pesquisa histórica brasileira - seja pelos temas que abordou (econômicos e sociais), seja por seu padrão de análise, claramente distinto do predominante até então. Nos anos vinte encontramos ainda alguns esboços de História Econômica nos trabalhos de Vitor Viana (de 1922) e de Lemos Brito (de 1923), que refletem, para Iglésias (1959), um crescente interesse pelo tema, embora sem representar ainda uma ruptura radical com a velha historiografia brasileira.

Foi sem dúvida nos anos trinta que ocorreu uma sensível renovação no pensamento social brasileiro. Novos autores foram então revelados por obras que propunham "novas interpretações" da história e da sociedade brasileiras. Oliveira Viana, Gilberto Freire, Sérgio Buarque de Holanda e Caio Prado Jr. produziram estudos que se tornariam clássicos na definição de outros caminhos para a compreensão da sociedade brasileira. Mas, também a História Econômica do Brasil teve novas e 
substanciais contribuições: Roberto Simonsen, J. F. Normano e, já nos anos quarenta, Caio Prado Júnior publicaram obras notáveis sobre a história econômica do Brasil, propondo efetivamente interpretações sobre o seu processo de desenvolvimento. Apesar das profundas diferenças entre esses autores, tinham em comum uma preocupação "interpretativa" que, em geral, se projetava em propostas "políticas".

A obra de Alice Canabrava distingue-se dos estudos desses autores em diversos sentidos: seus objetos, métodos de pesquisa e fontes utilizadas refletiam em grande medida a formação que tivera no curso de História e Geografia da Faculdade de Filosofia da USP.Tratava-se, antes de mais nada, de estudos monográficos que se contrapunham claramente à tendência de produzir grandes interpretações. A esse respeito, vale reproduzir um comentário de Sérgio Buarque de Holanda:

"Se os modernos estudos de história econômica, tais como, entre nós, vem praticando especialmente Alice P. Canabrava, podem ser responsabilizados até certo ponto pela renúncia às vastas sínteses em proveito de trabalhos monográficos, ninguém negará que tendem a oferecer, por outro lado, algumas vantagens claras. Entre elas a de contribuírem para desfazer as ilusões raciais, políticas ou nacionais que por tanto tempo vem perseguindo certos espíritos." (Holanda, 1952).

Quanto aos métodos de pesquisa e à preferência pelas fontes primárias, pode-se sugerir a incorporação de um padrão de investigação típico da escola francesa dos Annales. Em resenhas sobre as duas primeiras teses de Alice Canabrava, Fernand Braudel e Vitorino Magalhães Godinho insistiam nessa identidade. Sobre O Comércio Português no Rio da Prata dizia Braudel:

"No tocante a estas regiões deserdadas, no começo de sua rude vida colonial, uma jovem historiadora brasileira,Alice Piffer Canabrava, formada e orientada, posso assegurar, pela leitura e conhecimento de nossos Annales, acaba de escrever um livro, seu primeiro livro. Com satisfação, posso dizer que se trata de um livro de grande importância." (Braudel, 1948:547).

Não era muito diferente a apreciação geral de Godinho a respeito da pesquisa sobre o acúcar nas Antilhas: 
das empresas, inclusive as grandes, mesmo quando organizadas na forma de sociedades anônimas, era familiar. O mercado de capitais também era muito pouco desenvolvido. Nessas circunstâncias, eram os lucros acumulados a principal fonte de financiamento industrial. Também decorria dessa situação o desvio de parte dos lucros para a especulação, particularmente com imóveis. Esse diagnóstico já era feito à época, como mostravam o relatório da Missão Cooke em 1942 (A Missão Cooke no Brasil, 1948:325,334-339) e as discussões acerca de várias propostas de organização de bancos de investimentos realizadas no Conselho Federal de Comércio Exterior (CFCE) e no Conselho Técnico de Economia e Finanças (CTEF) ocorridas no período (Diniz, 1978:134-145).

A criação da carteira de Crédito Agrícola e Industrial do Banco do Brasil (CREAI) foi uma tentativa de contornar essa situação. Inicialmente, a área de atuação da CREAI abarcava o financiamento da entressafra, da aquisição de máquinas agrícolas, da aquisição de matériasprimas e da reforma de máquinas industriais. Logo, porém, passou a financiar projetos de expansão de indústrias. Os financiamentos para a aquisição de equipamentos e máquinas industriais tinham prazos de até dez anos; eram portanto empréstimos de longo prazo. A CREAI em pouco tempo, ganhou importância, chegando seus empréstimos às atividades produtivas a representar mais de $40 \%$ dos empréstimos totais do Banco do Brasil a partir de 1942 (Malan, 1977:242-252;Villela e Suzigan, 1973:187-188). Contudo, a CREAI não foi uma solução para os problemas nessa área, pois a carência de financiamento de longo prazo continuaria sendo uma das principais questões da industrialização.

Outra medida importante para enfrentar os problemas relativos ao financiamento dos investimentos, também adotada em 1937, foi a flexibilização da legislação referente à aplicação de recursos dos Institutos de Aposentadoria. Passou a ser permitido a esses Institutos empregar parte de seus recursos em investimentos com garantias hipotecárias (regulamentação do Decreto-lei n. ${ }^{\circ}$ 1.918, de 27/08/1937). No início de 1940 , cerca de " $20 \%$ do total das hipotecas [desses Institutos] provinham de terrenos e edificações para fábricas, e outros imóveis com fins industriais" (A Missão Cooke no Brasil, 1948:325 e 336-339).

No que diz respeito ao financiamento público, a principal medida parece ter sido o já mencionado Plano Especial, que não deixava de ser uma forma nova de financiar a ampliação dos gastos públicos sem a necessidade de reforma no sistema tributário. A principal fonte de recursos desse plano consistia no imposto sobre as operações cambiais, 
instituído em dezembro de 1937 no decreto que estabelecia o monopólio do câmbio (Costa, 1971). Esse plano e sua forma de financiamento foram uma das primeiras tentativas, depois largamente utilizadas ao longo do Estado Novo, de ampliar e flexibilizar o gasto público através de fundos, impostos específicos e programas paralelos ao orçamento federal, fazendo da política fiscal um instrumento de desenvolvimento (Coutinho e Szmrecsányi, 1987:7-11).

A CREAI, o fundo de investimento formado com o imposto sobre operações cambiais, a flexibilização da legislação acerca dos fundos dos Institutos de Aposentadoria e o Plano Especial, como forma de constituir um esquema de financiamento fundamentalmente calcado em capitais nacionais, eram claramente insuficientes. A carência de recursos parece ter sido permanente no período. Mas, esse tosco esquema de financiamento não deixa de ser um outro forte elemento que sugere que o governo Vargas flertava com a possibilidade de um desenvolvimento nacional autônomo naquele momento.

Entretanto, Vargas parece ter vacilado em seguir esse caminho. A idéia de o capital estrangeiro ser fundamental para o desenvolvimento nunca foi abandonada, e não foram adotadas efetivamente as medidas nacionalistas preconizadas na Constituição.Vargas procurava, nessa época, muito mais estabelecer os parâmetros para uma nova forma de relacionamento com o capital estrangeiro do que assumir uma posição xenófoba. Em seus discursos, afirmava que o capital externo era bemvindo desde que se submetesse às leis brasileiras, não almejasse lucros exorbitantes e contribuísse para o desenvolvimento do País, o que implicava em investimentos que não reproduzissem a inserção do Brasil na economia mundial como país agrário-exportador (Corsi, 1997). No exato momento em que Vargas radicalizava sua postura nacionalista com a moratória da dívida externa e com a outorga de uma Constituição que restringia sobremaneiza o espaço do capital estrangeiro na economia brasileira, entabulava negociações com o Export and Import Bank a fim de obter créditos para a implantação da grande siderurgia no Brasil (GV 37.10.28/1; GV 37.12.06).

A situação ganhava complexidade porque a definição de um projeto de desenvolvimento entrelaçava-se com a questão das alianças externas do Brasil. Um dos aspectos dessa questão consistia no fato de que o problema do financiamento do desenvolvimento não residia apenas na mobilização de capitais nacionais: implicava também no financiamento das importações de bens de capital e matérias-primas (que não eram produzidos internamente devido ao relativamente acanhado setor in- 
oposição ao latifúndio que dominava a vida econômica da América espanhola. Mais do que isso:

"Podemos portanto dizer que, na base da evolução complexa que provocou no século XVII o comércio de contrabando, evolução que se processou no terreno social, econômico e político, estavam em germe os aspectos fundamentais que caracterizaram a Argentina na época da Independência." (Canabrava, 1984b:189-191)

Percebe-se, portanto, que o estudo de Alice Canabrava sobre o comércio português na região do Prata permitiu-lhe, não só compreender como se processou a formação econômica, social e política dessa região, mas também entender de que modo esses elementos acabam por se contrapor à condição colonial imposta pela Coroa espanhola.

O Aćucar nas Antilhas (1697-1755) trata de outra situação colonial americana: a das ilhas inglesas e francesas do mar das Antilhas. Como se sabe, no século XVII, ao serem expulsos de Pernambuco, os holandeses procuraram implantar nas Antilhas a produção açucareira - não em seus próprios domínios e sim como intermediários para os colonos ingleses e franceses. Com base em ampla documentação manuscrita, oriunda de arquivos nacionais e estrangeiros (em especial da Biblioteca do Congresso dos Estados Unidos), em fontes primárias impressas e ainda em fontes secundárias, Alice Canabrava reconstituiu o desenvolvimento da produção açucareira nas Antilhas, levando em conta a base geográfica, os aspectos técnicos, os meios de financiamento e a questão do mercado. Mereceu uma especial atenção dela a minuciosa descrição dos aspectos técnicos da produção antilhana que, em conexão com seus elementos sociais, demonstram "a unidade do sistema colonial praticado pelas metrópoles produtoras de açúcar". Ou seja, havia uma enorme semelhança entre a produção açucareira no Brasil e nas Antilhas - não só no plano técnico, mas também nas características das sociedades que daí emergiram. Ao mesmo tempo, observou uma diferença fundamental que, mais uma vez, apontava na direção da superação da condição colonial das diferentes áreas da América:

"Daí pode-se perceber conseqüências profundas no desenvolvimento político. No Brasil, onde desde o século XVII se formara uma classe de senhores rurais ligados à terra e enobrecidos por ela, madrugaram os movimentos nacionalistas. As possessões antilhanas francesas e inglesas permaneceram, em sua quase totalidade, votadas à condição de colônias européias. A exceção quanto a Santo Domingo é particularmente ilustrativa: aí vamos encontrar, mais do que em qualquer outra parte, no século XVIII, o senhor de engenho das colônias francesas. Lembremos, todavia, que o grupo responsável pela revolução de independência e que se apossou do poder, constituiuse principalmente de homens de cor, ou seja, de mestiços descendentes de escravos." (Canabrava, 1981: 246).

Mais uma vez, portanto, a conclusão da Autora apontava na direção do rompimento (ou não-rompimento) do vínculo colonial a partir das condições econômicas, sociais e políticas da colonização.

Em sua tese de cátedra — sobre o algodão em São Paulo — parecenos estar presente a mesma preocupação, embora o objeto de estudo não mais se situe na época propriamente colonial. Tendo por base uma ampla documentação primária - como a correspondência dos Conselhos Municipais com o Presidente da Província, e as notícias publicadas nos jornais da época - Alice Canabrava revela o processo de desenvolvimento da cultura do algodão em São Paulo, entre 1861 e 1875, como reflexo dos problemas de mercado gerados pela Guerra Civil norteamericana. Foi-lhe possível, assim, reconstituir os aspectos mais gerais da expansão e da decadência do algodão em São Paulo, bem como reviver aspectos expressivos da vida e da luta quotidiana dos produtores diante dos desafios representados pela nova produção. É inegável que a cultura do algodão respondia às características da economia brasileira como definidas desde o início da colonização:

"Sendo orientada a economia brasileira, desde os primórdios da história colonial, exclusivamente para as necessidades dos mercados do exterior, a produção algodoeira paulista havia seguido as vicissitudes daqueles mercados, conforme a tradição já estabelecida pelos outros produtos nacionais. Dessa maneira, havia crescido e declinado rapidamente, condicionada, de modo estrito pelas necessidades das indústrias têxteis européias, principalmente as da Inglaterra." (Canabrava, 1984a:291-292).

Cumpre notar, no entanto, que a explicação do declínio da cultura do algodão não se limitava ao mero reflexo do que ocorria no exterior. Relatou a respeito os notáveis esforços no sentido de evitar esse declínio. A construção da Estrada de Ferro Sorocabana por iniciativa de um comerciante de algodão - Luiz Matheus Mailasky — teve por objetivo 
reduzir os custos de transporte e facilitar a exportação do produto. Igualmente importante foi o estabelecimento, até 1875 , de seis fábricas de tecidos, próximas aos centros produtores do algodão, indicando já uma certa vitalidade da economia paulista à época e um engajamento na defesa da produção algodoeira. Estas iniciativas no entanto mostraramse insuficientes para impedir o declínio da produção algodoeira em São Paulo, decorrente dos elevados custos de produção e de problemas que a qualidade do produto apresentava para o comprador europeu (relativos tanto ao tipo da fibra quanto à forma de beneficiamento). Entendeu Alice Canabrava que a estrutura social da produção algodoeira, em grande parte fundada na pequena propriedade, desprovida de recursos financeiros, dificultou a solução desses problemas:

"Na essência, portanto, das questões técnicas, que explicam, em grande parte, a perda dos mercados europeus importadores do algodão paulista, predominam os problemas financeiros que dificultaram a solução rápida daquelas questões, como exigiam as novas condições do mercado europeu após o término da guerra civil americana." (Canabrava, 1984a:293).

Evidencia-se, desse modo, que a explicação do declínio da produção exportadora não aparece, em Alice Canabrava, como simples fruto do fim de um ciclo e reflexo das condições do mercado externo, e sim como resultado de uma complexa interação entre fatores externos e internos, num processo que aponta no sentido de superar a condição colonial (por exemplo, pelo estabelecimento de indústrias de tecidos de algodão). ${ }^{12}$

Não é necessário lembrar que essa preocupação imanente à obra de Alice Canabrava nos anos quarenta refletia o próprio momento histórico vivido pelo País desde 1930, quando a crise do setor exportador colocou em questão o caráter colonial da economia brasileira, suas implicações sociais e políticas e, afinal, o problema da superação da herança colonial. Nesse sentido, parece-nos que a pesquisa histórica de Alice Canabrava respondeu, à sua maneira, às inquietações da época, do mesmo modo que outros autores citados (em particular, Roberto Simonsen e Caio Prado Júnior). É certo que o fez de forma peculiar,

12 Uma avaliação mais minuciosa das três teses de Alice Canabrava pode ser encontrada em Mello, Nozoe e Saes(1985). 
sem propor generalizações amplas pois, como dizia nas suas próprias palavras:

"Só me sinto segura quando apoiada em documentos. Não sou pessoa de realizar grandes vôos fora do material. Creio que é um problema de temperamento." (Canabrava, 1997:160).

Entretanto, é inegável que o vasto conhecimento histórico acumulado nos anos trinta e quarenta levou-a à elaboração, nos anos cinquenta e sessenta, de alguns trabalhos de síntese em que, ao lado de uma base documental sólida e muitas vezes original, permitiu-se alguns "grandes vôos". Podemos lembrar a respeito três deles. Primeiro, a sua Introdução ao livro de Antonil, Cultura e Opulência do Brasil, cujos originais datam de 1711. Através desta Introdução, o leitor pode situar-se no meio econômico e social em que Antonil escreveu seu texto e, assim, compreendê-lo melhor. Mas apresenta também uma explicação minuciosa das técnicas referidas porAntonil, conferindo a essa Introdução o caráter de um texto efetivamente original. Ao lado dela, publicou dois capítulos bastante conhecidos da coleção História Geral da Civilização Brasileira, organizada por Sérgio Buarque de Holanda. Trata-se de "A Grande Propriedade Rural", no tomo referente à época colonial, e de "A Grande Lavoura", no volume que se ocupa da economia do período imperial. Ambos associam a uma visão mais geral da atividade agrícola no Brasil o cuidadoso estudo das técnicas utilizadas nas principais produções, e representam contribuições de inegável valor para o conhecimento de nossa história econômica.

Naqueles anos, Alice Canabrava também se dedicou a outros trabalhos típicos do oficio de historiador, elaborando estudos bibliográficos (colaboração no Manual Bibliográfico de Estudos Brasileiros, dirigido por Rubens Borba de Moraes; Roteiro Bibliográfico da História do Brasil); análises da historiografia (em especial das obras de Varnhagen, Martius e Capistrano de Abreu), e de questões metodológicas (como "História e Economia").

Nos anos setenta, um novo núcleo de pesquisa, em certa medida também pioneiro, revela-se nas publicações de Alice Canabrava. Tratase de seus estudos quantitativos sobre a distribuição da riqueza em São Paulo (Capitania e Província) entre meados do século XVIII e as primeiras décadas do século XIX. Com base em documentação manuscrita, pertencente principalmente ao acervo do Departamento de Arquivo do Estado de São Paulo (Inventário de Bens Rústicos e Maços 
de População), a historiadora pôde traçar quadros nítidos da distribuição das terras, da riqueza e dos escravos. Alguns resultados marcantes merecem registro: o predomínio da riqueza mercantil (homens de negócio e mercadores), mesmo num momento de decadência (1865/67), a indicar o peso da atividade comercial em São Paulo (Canabrava,1972a); a extrema concentração da propriedade fundiária em 1818, assim como a de escravos, apesar da existência de um grande número de pequenos proprietários na sociedade paulista (Canabrava, 1972b e 1976).

Estas breves observações não fazem jus ao brilho da reconstrução histórica da sociedade paulista que é feita em conexão com dados quantitativos, e que se contrapõem a algumas interpretações tradicionais sobre São Paulo daqueles tempos (como a da "democracia" paulista originária). Embora essa documentação já tivesse sido explorada (mais com vistas a análises qualitativas), e que os estudos quantitativos em história já estivessem sendo desenvolvidos na época (como no caso da demografia histórica e dos índices de preços), parece-me que aqui também Alice Canabrava se insere numa vertente pioneira pela forma que utilizou a informação quantitativa com vistas ao problema da distribuição. Extensas pesquisas adicionais sobre os temas acima (em especial sobre a posse de escravos) foram realizadas em fontes diversas (inclusive em cartórios), mas infelizmente não se consubstanciaram em novos textos de sua autoria, ou num livro que consolidasse os resultados a que chegou em vários anos de pesquisa.

Entendo que esta breve revisão de algumas das obras de Alice Canabrava fornece ao leitor o quadro em que se desenvolveu a sua pesquisa em História Econômica. Além das contribuições específicas aos temas que estudou, seus trabalhos sugerem modelos de abordagem para a disciplina, associando a erudição histórica, a revelação de fontes primárias muitas vezes inéditas e um tratamento analítico rigoroso. $\mathrm{O}$ vasto crescimento da pesquisa em História Econômica nas últimas décadas não foi capaz de tornar obsoletas as obras de Alice Canabrava. Os jovens pesquisadores de nossa história econômica podem encontrar em suas obras verdadeiros modelos de exploração de fontes primárias articulados à explicação de processos históricos específicos. Igualmente exemplares são as suas análises quantitativas que, ao tratar de forma adequada os dados disponíveis, e sem se pautar por rígidos padrões teóricos formulados sem contato com a realidade histórica particular (nos moldes, por exemplo da New Economic History), inauguraram uma importante vertente de estudos sobre a distribuição da riqueza no Brasil do século XVIII e do XIX. Nesse sentido, as obras deAlice Canabrava 
mantêm-se atuais pelas explicações históricas que propuseram, e também como referência metodológica para novas pesquisas sobre a história econômica do Brasil.

\section{Um Breve Comentário Final}

O pioneirismo de Alice Canabrava, que repetidamente procuramos mostrar ao longo deste texto, insere-se em processo de mudança que afeta a sociedade brasileira a partir de 1930. Certamente, como menina do Interior, ela poderia ter-se acomodado e permanecer à parte das transformações sociais e culturais que se processavam nos centros urbanos maiores. No entanto, sua determinação levou-a a ter um papel em significativos momentos da transformação social e de sua profissão.

Seu ingresso na Universidade de São Paulo, na primeira geração de alunos da Faculdade de Filosofia foi expressiva: ela se deslocou da sua cidade natal e integrou-se a um dos mais importantes movimentos culturais do País naquele período. Pode-se dizer mesmo que, como professora, participou da construção da Universidade, inclusive na fase de formação da Faculdade de Ciências Econômicas e Administrativas, da qual foi diretora, em sua fase de consolidação. Procuramos mostrar também o seu pioneirismo enquanto mulher, galgando os degraus da carreira universitária numa época em que a presença feminina no mercado de trabalho em geral, e particularmente em postos elevados na hierarquia, era rara e até certo ponto hostilizada.

É,porém, como historiadora que queremos ressaltar o seu pioneirismo. Sem dúvida, ela teve a rara oportunidade de contar com mestres - em especial Braudel e Monbeig - que a colocaram em contato com o que havia de mais avançado na pesquisa em suas respectivas disciplinas. Talvez mais do que outros de sua geração, ela soube vencer o desafio de incorporar esses ensinamentos e atualizar-se constantemente, trazendo à sua pesquisa o que havia de novo e sólido na área de História Econômica. Desse modo, suas obras apresentam, invariavelmente, esse caráter pioneiro na exploração de temas importantes e na incorporação de novas abordagens.

Houve, portanto, algumas felizes coincidências: a criação da USP com um momento em que Alice Canabrava tinha disponibilidade e disposição para nela ingressar; o contato com a Escola dos Annales no momento em que iria iniciar sua carreira acadêmica; a possibilidade de ascensão na carreira, pela expansão da Universidade, apesar da resistência masculina; o ingresso numa Faculdade de Economia que lhe pôde 
dar apoio e estímulo na elaboração de uma história quantitativa.É claro, no entanto, que essas felizes coincidências não teriam resultado em nada se não houvesse, da parte de Alice Canabrava, a capacidade e a determinação para enfrentar enormes desafios pessoais e intelectuais. É aí que se situa precisamente o seu pioneirismo, pelo qual tratou de percorrer caminhos inéditos (para uma historiadora e para uma mulher), ainda que possíveis em situações históricas específicas. Foi esse pioneirismo que a levou à sua carreira como professora, e a produzir uma obra em História Econômica que se coloca como uma referência obrigatória na historiografia brasileira.

\section{Bibliografia}

Blay, Eva A. e Lang, Alice B. S. G. A mulher nos primeiros tempos da Universidade de São Paulo. Ciência e Cultura, 36 (12), 1984.

Braudel, Paul Fernand. Du Potosi a Buenos Aires: une route clandestine de l'argent

(Fin du XVIe siècle, début du XVIle siècle). Annales, III (4), 1948.

Canabrava, Alice Piffer. O Comércio Português no Rio da Prata, 1580-1640. São

Paulo: Faculdade de Filosofia, Ciências e Letras da Universidade de São Paulo, 1944.

- A Indústria do Aşúcar nas Ilhas Inglesas e Francesas do Mar das Antilhas, 16971755. São Paulo: s.c.p., 1946.

- O Desenvolvimento da Cultura do Algodão na Província de São Paulo, 1861-1875.

São Paulo: Martins, 1951.

- A Grande Propriedade Rural, in Sérgio Buarque de Holanda (dir.). História

Geral da Civilizaşão Brasileira. Tomo I. Volume 2. A Época Colonial: Administração,

Economia, Sociedade. São Paulo: Difusão Européia do Livro, 1960.

- Introdução e Vocabulário. Antonil, André João (João Antonio Andreoni).

Cultura e Opulência do Brasil por suas drogas e minas. São Paulo: Companhia Editora Nacional, 1967.

- A Grande Lavoura, in Sérgio Buarque de Holanda (dir.). História Geral da Civilizaşão Brasileira. Tomo II.Volume 4. O Brasil Monárquico: Declinio e Queda do Império. São Paulo: Difusão Européia do Livro, 1971.

Roteiro Bibliográfico da História do Brasil. Instituto de Estudos Brasileiros/

USP. Encontro Internacional de Estudos Brasileiros. São Paulo: IEB/USP, 1971.

- Uma economia de decadência: os níveis de riqueza na capitania de São

Paulo, 1765/67. Revista Brasileira de Economia, 26 (3), 1972a.

- A repartição da terra na capitania de São Paulo, 1818. Estudos Econômicos, 2 (6), $1972 b$.

- Terras e Escravos, in Peláez, C. M. e Buescu, M. (coord.). A Moderna História

Econômica. Rio de Janeiro: APEC, 1976.

- Varnhagen, Martius e Capistrano. Anais do III Congresso de Estudos Teuto-

Brasileiros. Porto Alegre: Universidade Federal do Rio Grande do Sul, 1980.

- O Açúcar nas Antilhas, 1697-1755. 2 ed. São Paulo: IPE-USP, 1981.

- (coord.). História da Faculdade de Economia e Administraşão da Universidade de 
São Paulo, 1946-1981, Volume Dois, Personália. São Paulo: Faculdade de Economia e Administração da USP, 1984.

Canabrava, Alice Piffer. O Algodão em São Paulo, 1861-1875. 2 ed. São Paulo: T. A. Queiroz, 1984a.

. O Comércio Português no Rio da Prata, 1580-1640. Belo Horizonte: Itatiaia; São Paulo: Edusp, 1984b.

- História e Economia. Literatura Econômica, 7 (1), 1985.

. Minhas reminiscências. Economia Aplicada, 1 (1), 1997.

O Caminho Percorrido. Depoimento apresentado em Simpósio sobre as mulheres nos primeiros tempos da Universidade de São Paulo. Texto datilografado (s/d). Capelato, M. H., Glezer, R., Ferlini,V. L. A. A Escola Uspiana de História. Capelato, M. H. R. (coord.). Produção Histórica no Brasil.Vol.1. São Paulo: Xamã,1995.

Daix, Pierre. Fernand Braudel: uma biografia. Rio de Janeiro: Record, 1999.

Godinho,Vitorino Magalhães. Industrie et commerce antillais: sur le sucre des Antilles. Annales, III (4), 1948.

Holanda, Sérgio Buarque de. História Econômica. S. Paulo: Folha da Manhã, 27 de agosto de 1948.

Iglésias, Francisco. Introdução à Historiografia Econômica. Belo Horizonte: Faculdade de Ciências Econômicas/Universidade de Minas Gerais, 1959.

Mello, Z. M. C., Nozoe, N. H. e Saes, F. A. M. de. Três pesquisas pioneiras em História Econômica (as teses universitárias de Alice Piffer Canabrava). Estudos Econômicos, 15, Número Especial, 1985.

Moraes, Rubens Borba e Berrien, William. Manual Bibliográfico de Estudos Brasileiros. Rio de Janeiro: Gráfica e Editora Souza, 1949.

Mota, Carlos Guilherme. Ideologia da Cultura Brasileira, 1937-1974. 4 ed, São Paulo: Ática, 1978. 